\title{
El arte de la novela ante la trampa del mundo: apuntes sobre la poética de la novela de milan Kundera frente a la crisis de la modernidad
}

\section{Resumen}

Guillermo Andrés Castillo Quintana*

Este artículo se concibe como una invitación-introducción al lector para que se aproxime a la obra novelística del escritor checo Milan Kundera (Brno, 1929-), en particular, a La broma (1967), El libro de los amores ridículos (1969), La vida está en otra parte (1969), El libro de la risa y el olvido (1978), La insoportable levedad del ser (1984) y La inmortalidad (1988). En este sentido, no se trata de un estudio exhaustivo de tales piezas, sino, antes bien, de la presentación de una hipótesis de lectura que pretende explicar a grandes rasgos su producción novelesca como una reacción estética frente al problema de la crisis de los valores modernos. Asimismo, este texto tiene por objeto reflexionar sobre la novela en calidad de instrumento indagatorio de la existencia humana y, especialmente, sobre su modo particular de ofrecer una interpretación al mismo tiempo lúdica y lúcida de algunos rasgos que supone la experiencia del mundo posmoderno.

Palabras clave: Historia, literatura y sociedad, Milan Kundera, novela, posmodernidad

\section{Abstract}

This is an invitation-introduction to the reader to approach to the novels of the Czech writer Milan Kundera (Brno, 1929-), especially, The Joke (1967), Laughable Loves (1969), Life is Elsewhere (1969), The Book of Laughter and Forgetting (1978), The Unbearable Lightness of Being (1984) and Immortality (1988). Therefore, this is not an exhaustive study of such pieces, but rather a general hypothesis that aims to explain its production as an aesthetic reaction to the crisis of modern values. Likewise, this text aims to comprehend novel as an investigative instrument of human existence and especially as a particular way of present a playful and lucid interpretation of some problems that supposes the experience of the postmodern world.

Keywords: History, literature and society, Milan Kundera, novel, postmodernity

\footnotetext{
* Profesional en Estudios Literarios de la Universidad Nacional de Colombia. Contacto: gacastilloq@unal.edu.co
} 


\section{Introducción}

El género novelesco, que "acompaña constante y fielmente al hombre desde el comienzo de la Edad Moderna" (Kundera, 1987, p. 15) se ha caracterizado por indagar sobre las condiciones elementales y básicas de la existencia humana. El descubrimiento de estas condiciones a lo largo del camino que nos lleva desde Cervantes y Rabelais hasta nuestros días es, entonces, de acuerdo a Hermann Broch, su moral (p. 16). Vista de otro modo, esta idea de novela implica tácitamente la atribución de unas funciones cognoscitivas, noéticas ${ }^{1}$ y de indagación antropológica (Chvatik, 1996, p. 24) a su "estructura artística global" ${ }^{2}$ e igualmente invita a pensar en el hecho, en apariencia obvio, de la existencia de una historia de la novela.

Ahora bien, esta historia de la novela aparece en directa oposición a la Historia (con mayúscula) de la humanidad. Es más, en palabras del mismo Kundera, la tradición novelística es una suerte de venganza contra la Historia a secas, "esa fuerza hostil, inhumana que, al no haber sido invitada, invade desde el exterior nuestras vidas y las destruye" (Kundera, 1994, p. 24). El gesto del autor de La insoportable levedad del ser, tras declarar su adhesión a la "herencia de Cervantes", es un modo de afirmar que, de forma coherente a su oficio, pertenece al curso de la historia de este género proteico y volátil que llamamos novela y, en general, al de la historia del arte: el sentido de la historia de un arte se opone al de la Historia a secas. Gracias a su carácter personal, la historia de un arte es una venganza del hombre contra la impersonalidad de la Historia de la humanidad. (1994, pp. 24-25)

Al ser propio del género novelesco el descubrimiento de las condiciones de la existencia humana, no sorprenderá entonces el hecho de que su historia se represente no en un unilateral trazo horizontal, sino en una suerte de mosaico o abanico de posibilidades y alternativas; si se admite aquí la explicación figurativa del asunto, el trazo horizontal obedece al dibujo que ha tallado para sí misma la Historia a secas de la humanidad, mientras que el mosaico, en contraparte, pone de manifiesto el carácter polivalente e inherente a la interpretación artística. Por supuesto, es de precisar que la función cognoscitiva y noética de la novela se explica en función del tipo de conocimiento particular al que permiten acceder las obras de arte en general, y, en específico, al tipo de experiencia estética que encaramos al momento de leer una novela, entendida, claro está, en calidad de "hecho sígnico" 3 , lo que a su vez implica, entre otras cosas, asumir la creación del mundo autónomo que se conoce por ficción literaria y la facultad que esta posee de generar nuevos sentidos. De lo anterior se deriva que la imagen del

1 Por función noética entiendo la capacidad particular de las obras artísticas de indagar sobre los aspectos relacionados con los modos en que se desarrolla y expresa el pensamiento humano. En cierta medida, el arte nos pone de cara frente a un tipo de saber y conocer de corte intuitivo, distinto, por tanto, del racional o cartesiano. Jan Mukařovský hizo uso extensivo de este concepto en sus estudios sobre la naturaleza de las obras artísticas y su calidad de hechos sígnicos y sociales.

2 Entiendo por estructura artística global de la novela al conjunto discreto formado por la estructura temática o significativa y su construcción formal. Este concepto puede ser evaluado desde la perspectiva del concepto de totalidad en la teoría del arte (Mukařovský, 2000b, pp. 290-302).

3 La comprensión de la obra de arte como "hecho sígnico" es, ante todo, una pugna por garantizarle el tipo de valoración que se merece, esto es, bajo la conciencia de su función estética. Jan Mukařovský anota con énfasis que "mientras el carácter sígnico de la obra de arte no esté suficientemente esclarecido, el estudio de la estructura de la obra artística permanecerá necesariamente incompleto. Sin una orientación al signo, el teórico del arte propenderá siempre a considerar la obra artística como una construcción puramente formal, o incluso como un reflejo directo ya sea de las disposiciones psíquicas o hasta fisiológicas del autor, ya sea de la realidad determinada expresada por la obra o de la situación ideológica, económica, social, cultural del medio social dado [...]. Solo el enfoque sígnico permitirá a los teóricos reconocer la existencia autónoma y el dinamismo esencial de la estructura artística y comprender el desarrollo del arte como un movimiento inmanente, pero en relación dialéctica constante con la evolución de los demás dominios de la cultura" (Mukařovský, 2000a, p. 93). 
mundo que surge de la ficción novelesca se mantiene esencialmente en el marco de las posibilidades y que, en este caso, "el sentido que la forma artística de la novela produce es, por la influencia de la función estética, esencialmente ambiguo; el mundo de la novela está, por lo tanto, caracterizado por la polisemia y la ambivalencia semánticas" (Chvatik, 1996, p. 24. El énfasis es mío).

Este carácter hipotético propio de la novela revela que su terreno no es el de la afirmación sino el de lo problemático. Del mismo modo, acentúa la distancia entre su historia y la de la Historia a secas. En la medida en que la novela descubre posibilidades y problemas de la existencia humana, mas nunca respuestas unívocas, es posible entender, a juicio de Kundera, el sentido de su historia: “el sentido de la historia de la novela es la búsqueda de este sentido, su perpetua creación y re-creación, que abarca siempre retrospectivamente todo el pasado de la novela" (Kundera, 1994, p. 25. El énfasis es mío). Por este motivo, el dibujo de la historia de la novela -como el de cualquier arte- no puede seguir el trazo univalente de la Historia; su constante redescubrimiento le impide, por definición, constreñirse a una visión de mundo monista y unilateral.

Ahora, esa mirada retrospectiva que hace la novela sobre sí misma -cabe indicar, a través del ejercicio individual de los novelistas- señala la profunda conciencia de la idea de tradición que han de tener sus cultores $\mathrm{y}$, por supuesto, la necesidad ineludible de que cada nueva novela entre en un constante diálogo con ella. Este diálogo, diríase, es uno de los compromisos éticos que el novelista asume al momento de trabajar en su proyecto estético particular una vez ha entendido que el valor de una obra particular solo puede sopesarse en el seno de la tradición, en otras palabras: a la luz de la historia de la novela (Kundera, 1994). Solo de este modo se hace posible evitar o repetir los logros anteriores, celebrar los nuevos descubrimientos y abrir otras líneas de interpretación novelesca de lo humano.

A mi entender, las grandes obras solo pueden nacer dentro de la historia de su arte y participando de esta historia. En el interior de la historia es donde puede captarse lo que es nuevo y lo que es repetitivo, lo que es descubrimiento y lo que es imitación, dicho de otra manera, en el interior de la historia es donde una obra puede existir como valor que puede discernirse y apreciarse. Nada me parece, pues, más espantoso para el arte que la caída fuera de su historia, porque es la caída en un caos en el que los valores estéticos ya no son perceptibles. (Kundera, 1994, p. 26)

\section{La novela frente a la máquina inhumana de la historia}

Sentado lo anterior, se hace preciso esclarecer qué parte de la historia sociocultural humana afrontó Kundera en calidad de novelista, para comprender no solo la dirección y la lógica de su producción literaria, sino también la ineludible relación que el género novelesco guarda con ella hoy en día. La impresión inicial no es muy alentadora. El mismo autor checo ha denunciado en más de una oportunidad que la novela ya no puede convivir con el actual espíritu del tiempo. Incluso, ha llegado a afirmar que el objeto de su amor por el arte ya ha perecido porque se ha evadido de su propia historia (Kundera, 1987). "Estar fuera de la historia de la novela" no es más 
sino otro modo de describir, desde las categorías explicativas del novelista, el espíritu de la contemporaneidad o, para algunos, posmodernidad -momento sociohistórico y existencial al que hemos ingresado sin mayor reparo-. Hablamos aquí de la era de la reducción. Por reducción entiendo: el tiempo en el que la modernidad entra en la fase de los corolarios y no tiene forma alguna de urdir siquiera un argumento incipiente para explicar la esencia y el origen de su pathos, pues también lo ha olvidado; tiempo en el que, por exigencia del modus vivendi contemporáneo, se le exige a la historia que ingrese en una etapa posterior, pero que no debería ser llamada posmodernidad, puesto que no guarda ya relación alguna con el espíritu de la modernidad; el tiempo del más arrollador "olvido del ser".

Si Kundera, como miembro adscrito a la herencia de Cervantes, es decir, al espíritu de la modernidad, entiende que incluso la novela ha sido acosada por las termitas de la reducción a tal punto que se ha desbocado de su propia historia, es posible deducir que su situación como sujeto histórico lo enmarca en una época en la que la modernidad se encuentra en los albores de la dehiscencia. Sin poder esclarecer cuál es el pathos del período subsecuente a los tiempos modernos, salvo la desconsoladora certidumbre de que no guarda ninguna relación con la idea de modernidad -y por este motivo hace del mundo un lugar hostil para la novela-, surge la pregunta por el sentido del género novelesco y de la misma creación de novelas en el escenario de un mundo que: 1) ha puesto a la novela y a todas las formas artísticas a merced de los medios de comunicación, esos "agentes de la unificación planetaria que canalizan el proceso de reducción [al distribuir] en el mundo entero las mismas simplificaciones y clichés que pueden ser aceptados por la mayoría" (Kundera, 1987, p. 28); 2) ha alienado y constreñido a la novela mediante su adhesión a los totalitarismos políticos e ideológicos (comunismos, fascismos) o a través del llamado "totalitarismo kitsch" (Padi1la, 2010); 3) ha sofocado al arte de la novela en una conciencia del tiempo que entiende la modernidad ya no en el sentido de un pathos, es decir, de una visión de mundo, sino en el sentido del hodiernus latino que traduce actualidad -un culto acrítico a lo inmediato y nada más que lo inmediato, amén- y que, por tanto, "reduce el tiempo al único segundo presente" (Kundera, 1987, p. 29) e imposibilita pensar en la lógica de la memoria, de la continuidad, de la historia, de la tradición; y 4) ha reemplazado la lectura de novelas por los periódicos, la radio, el cine, la televisión, internet, esto es, por la inmensa generalidad de los medios de comunicación de masas sobre los cuales Walter Benjamin ha señalado que "reemplazan el relato de las 'informaciones' por noticias concretas [sin dejar] a sus receptores espacio para la sorpresa, la reflexión y el sueño" (Chvatik, 1996, p. 9). ¿Cómo habrá de exigir la novela su terruño en este momento de cambio cultural? y ¿cómo habrán los novelistas de garantizar la pervivencia de su arte, su autonomía y su tradición?

La respuesta parece sugerirla el mismo Kundera, y es de cuidado, pues adopta el cariz de una confrontación: "si todavía quiere seguir descubriendo lo que no está descubierto, si aún quiere 'progresar' en tanto que novela, no puede hacerlo sino en contra del progreso del mundo" (Kundera, 1987, p. 30). Si hoy en día el progreso del mundo implica el gobierno de la ausencia de la memoria, del imperio de lo inmediato, de la masificación de las sociedades, la unificación globalizadora y de la decadencia kitsch, el espíritu de la novela, y por extensión de todas las formas artísticas, solo puede entenderse en calidad de una crítica a esa nueva dirección del mundo. 
A la luz de lo anterior, surge un nuevo interrogante: ¿Qué características adoptaría tal crítica? Con la intención de iluminar este asunto, desearía traer aquí "la metáfora del cuadrante" sobre la que discurre la sexta parte de su novela La inmortalidad:

[Cuando] las manecillas habían recorrido ya el cuadrante de su vida sexual, [Rubens se halló] fuera del tiempo del cuadrante. Hallarse fuera del tiempo del cuadrante no significa ni el fin ni la muerte. En el cuadrante de la pintura europea también había sonado ya la medianoche y sin embargo los pintores seguían pintando. Estar fuera del tiempo del cuadrante solo significa que ya no pasa nada nuevo ni importante. (Kundera, 1990, p. 383)

El oficio del novelista en el tiempo de "las novelas fuera de la historia de la novela" puede esclarecerse al retomar la metáfora del cuadrante para nuestro beneficio: Kundera -y por extensión los novelistas de nuestro tiempo- escribe cuando el cuadrante de la novela está en la medianoche. Solo un gesto, acaso el rasgo fundamental de la novelística kunderiana, autoriza y motiva el oficio y el arte de urdir novelas bajo estas condiciones: el ejercicio de la memoria y la reflexión crítica. Con estas herramientas se iniciará el camino de su búsqueda estética y las armas que empuñará desde el universo de la novela contra el mundo que le ha mostrado su cara más hostil.

Entiendo la materialización concreta de este gesto en un aspecto que quisiera desarrollar de aquí en adelante, a saber: la toma de conciencia del arte de la novela desde el interior mismo de las novelas; la novela y el arte de su composición como temas novelísticos: un gesto de remembranza. Veamos: al situarnos en un momento en que la novela se salió del cauce de su historia y, por lo tanto, quedó desahuciada de la conciencia de su tradición, solo a partir de una indagación sobre sí misma podría recobrar su sentido. Desde esta perspectiva, la producción novelística kunderiana exhibe primordialmente un balance crítico y meditado de lo que ha sido el género hasta el momento de cambio y crisis cultural que vive el autor como sujeto histórico. Por supuesto, dicho balance no se expresa como un producto teórico sino en los términos de la experiencia estética que ofrece cada una de sus novelas. Intentaré una definición. Búsqueda estética y formal kunderiana: un camino que conduce al reencuentro con la tradición del género novelesco.

\section{El género novelesco como tema novelesco}

El modo de proceder kunderiano a la hora de conceder a la novela y su arte de la composición el carácter de tema-problema no es muy distinto del que asume cuando aborda cualquier otro aspecto de tipo filosófico o antropológico. Dependerá de cómo procede para insertar este motivo particular dentro del conjunto de asuntos que también se ponen a funcionar dentro de la estructura significativa de sus obras - piénsese, por ejemplo, en el enfrentamiento del hombre con la historia (La broma), la edad lírica (La vida está en otra parte), la levedad y el peso (La insoportable levedad del ser), la inmortalidad (La inmortalidad), entre otros - , y de qué manera es manipulado el asunto en el plano de la estructura narrativa para alcanzar sentido pleno en la estructura global. ¿Quién propone las disertaciones sobre la novela?: ¿el narrador; un personaje? ¿Lo 
hace a través de la perspectiva lúdica, irónica y reflexiva propia de la actitud del ensayista -la misma que le autoriza a suspender la historia o la anécdota contada en forma de digresión para evaluar un tema en el marco de la novela-? ¿Aparece acaso sugerido de forma tácita en la estructura formal del texto literario? Piénsese en los principios compositivos y en aspectos de técnica narrativa tales como la distribución de las partes de la novela, la perspectiva y la voz que domina cada uno de los capítulos (narrativa, digresivo-ensayística, monologal), el tempo narrativo, la composición polifónica ${ }^{4}$-entendida no desde la perspectiva bajtiniana, sino al estilo de una estructura contrapuntística que, de forma coherente, pone en relación motivos, temas, líneas y tonos discursivos que pueden ser adoptados ya sea por diferentes personajes o formas del discurso y que vienen a encajarse en la caja de la novela-, entre otros.

Si bien la novela como tema dentro de la estructura significativa de las obras no aparece en todos los textos novelísticos de Kundera -de hecho, este va haciéndose más explícito paulatinamente conforme nos acercamos a La inmortalidad (1990)-, siempre se manifiesta como una preocupación compositiva que afecta las elecciones formales $y$ narrativas del autor a la hora de concebir sus novelas. Me explico, aunque en textos como El libro de los amores ridículos y La broma la novela nunca se esboce como un problema a nivel temático, sí se insinúa en la medida en que el autor pretende dirigir la atención del lector a los pormenores de la estructura narrativa, dado que allí se encarna su concepción del arte de narrar -una actividad que, como se ha dicho, se comprende desde el horizonte de una tradición-. Por ejemplo, el gesto de afirmar que El libro de los amores ridículos es una novela resultó en un gran revuelo para la crítica, en la medida en que sus siete relatos, muchas veces comprendidos como cuentos independientes, no están emparentados en un único hilo narrativo -la única brecha que débilmente parece evidenciar un modo de continuidad de la trama es el caso de la historia del doctor Havel que aparece en dos de los relatos-. El gesto pretendía validar otro modo de unidad novelesca: la unidad temática del problema existencial examinado ${ }^{5}$. Lo anterior, a su vez tiene elocuentes implicaciones si se mira desde la perspectiva de la historia de la novela, a saber, que el autor no parte del modelo de composición decimonónico, sino de lo que Chvatik describe como: "historias interesantes y en sus formas sencillas tales como la anécdota, la broma, la mistificación y el folletín" (1996, p. 14). En este sentido, es plausible entender $E l$ libro de los amores ridículos, desde el horizonte de la terminología musical, como un texto de tema $y$ variaciones, en el que dichas variaciones vienen expresadas en la extensa gama de estrategias narrativas que el autor empleó para construir cada relato.

Fue precisamente la unidad temática de El libro de los amores ridículos, sustentada sobre el tema recurrente de la mistificación, el juego del amor y las paradojas de los donjuanes tardíos, la que le permitió desplegar la rica variedad narrativa y formal en sus diferentes partes. Cada una de las siete historias tiene una

4 Para una aproximación más cercana a este aspecto de la narratividad kunderiana se sugiere la lectura de la segunda parte del libro de Iván Padilla Milan Kundera y el totalitarismo Kitsch: dictadura de conciencias y demagogia de sentimientos (2010), titulado "Narratividad y fugacidad en la novela de Milan Kundera".

5 "Por ser un arte temático, el arte de la novela autoriza al novelista a estructurar su obra alrededor de temas y no alrededor de la unidad de acción, la psicología de los personajes, la verosimilitud, o cualquier otra convención novelesca. Para Kundera, la coherencia y la unidad de la novela se aseguran por algo mucho más profundo que las convenciones, a saber, 'la unidad temática'. Este es, tal vez, el aporte estético más significativo que Kundera realiza al fusionar la técnica novelesca y la técnica musical" (Padilla, 2010, p. 58). 
estructura narrativa distinta, lo que hace de la obra una especie de muestrario de los modos narrativos que luego desarrolló el autor en las distintas novelas. Lo mismo puede decirse sobre los motivos: están aquí presentes en esencia, todos los futuros motivos de las posteriores novelas de Kundera, aunque naturalmente de manera fragmentaria, no en su forma desarrollada de estructuras temáticas. (Chvatik, 1996, pp. 43-44)

Contrario al movimiento lineal de una única voz que gobierne la estructura narrativa de principio a fin, como es común en la novela decimonónica, Kundera, con su gesto, manifiesta que la novela es más bien un banquete de formas, de voces y de formas de contar; su pulsión inicial es pasar revista de una extensa gama de posibilidades formales, intención que se entiende aquí como un primer rasgo, dentro de su producción, que pone en cuestión el problema del arte de la novela. Por supuesto, este ánimo tiene también un profundo significado que alude al tema de la tradición, pues no de otro lugar sino de la galería misma de descubrimientos formales que se exponen en el museo de la historia de la novela fue que Kundera aprendió y partió en su propio camino de búsqueda estética en pos de nuevos horizontes.

La broma exhibirá, de acuerdo a Chvatik, "un tipo de polifonía a cuatro voces" (1996, p. 57) -sustentada en los cuatro narradores de la novela: Ludvik, Helena, Jaroslav y Kostka- que rememora un pasado muy concreto de la historia de la música: el periodo de la polifonía vocal que tuvo su apogeo entre los siglos XIV y XV en las formas del motete eclesiástico y el madrigal -incluso en las atenciones que hace a la historia de la música, Kundera se muestra muy cercano a un periodo particular, el barroco, especialmente a la fuga, forma composicional de la música que ensalza como un procedimiento de inigualable calidad estética, también de naturaleza polifónica - . Esta detenida atención que presta a la música como discurso artístico capaz de entablar relaciones semióticas y formales con la técnica literaria es, en términos de Padilla, uno de los grandes aportes kunderianos al arte de composición novelesca (2010, p. 58). La Broma, aun sin discurrir expresamente sobre la novela como tema, sí manifiesta las posibilidades de diálogo que la estructura del arte novelesco puede entablar con otras estructuras artísticas, como es el caso de la música.

La estructura polifónica de La Broma demuestra, de nuevo, la intensidad con la cual Kundera trabajó en pos de alcanzar una forma narrativa que restituyera la atención perdida en la tradición del género. El diseño musical de la forma de su novela es un gesto que instiga a prestar atención al arte de la composición:
Del mismo modo en que Janacek se liberó de la técnica compositiva tra- dicional, el novelista debe destruir en su cabeza el "ordenador" de las reglas novelescas: "liberar la novela del au- tomatismo de la técnica novelesca, del verbalismo novelesco, darle densidad". (Chvatik, 1996, p. 63) ${ }^{6}$

Si pasamos ahora al marco de las cuatro grandes novelas kunderianas, aquellas que representan de algún modo una cima dentro de la llamada búsqueda estética del autor y que estabilizan el horizonte de sus preocupaciones temáticas y formales, a saber, La vida está en otra parte (1969), El libro de la risa y el olvido (1978), La insoportable levedad del ser (1984) y La inmortalidad (1988), es 
de señalar que en ellas la voz del narrador-autor, tan célebre por sus intervenciones digresivas y de corte reflexivo, se convierte en uno de los rasgos más característicos de este periodo de su novelística. A su vez, debe precisarse que la intensificación de esta voz trae consigo una consecuencia muy significativa: el debilitamiento paulatino de la historia contada (la trama). De nuevo, acaso con la intención de volver la mirada sobre la época de El libro de los amores ridiculos, la estructura temática, más que la unidad de acción, será la que garantizará la unidad de la estructura global, con el agravante que, en esta oportunidad, la novela kunderiana abrirá el camino al tono ensayístico, irónico y humorístico encarnado en la figura del narrador-autor que, incluso en La inmortalidad, alcanza a abrigar una tercera máscara dentro del universo ficcional: la de un personaje inmerso en la trama novelesca.

Igualmente, este narrador-autor digresivo y reflexivo, que de forma intempestiva se autoriza a sí mismo para suspender el trayecto de la trama con el fin de introducir sus comentarios, debe entenderse como un gesto que retrotrae, esta vez, un periodo muy concreto de la historia de la novela. Kundera regresa con esta estrategia narrativa a los siglos XVII y XVIII, el tiempo de Rabelais, Sterne y Diderot:

Recuerdo mi primera lectura de Jaques el fatalista; encantado con esa riqueza audazmente heteróclita en la que la reflexión se codea con la anécdota, en la que un relato enmarca a otro, encantado con esa libertad de composición que se burla de la regla de la unidad de acción. (Kundera, 1994, pp. 27-28)

Ese tono reflexivo y de carácter digresivo, muchas veces interpretado de forma errónea y parcial por la crítica como una simple intensión de escribir filosofía, debe entenderse como otro modo de prestar atención a la historia de la novela. Ahora, incrustado en el siglo xx, Kundera señala con tino que esta remembranza debe empatar con una conciencia clara de las enseñanzas referentes a la rigurosidad de la composición del siglo de la novela, el XIX. El autor de La insoportable levedad del ser observa la comunión de la perspectiva lúdica dieciochesca y la austeridad decimonónica en la narrativa de los autores centroeuropeos de principios del siglo veinte, especialmente en Kafka, Broch y Musil -probablemente, junto a Diderot, sus escritores más queridos-.

Ahora bien, respecto al asunto de la novela como tema, el carácter de ese narrador-autor es una pieza clave para comprender de qué modo se integra definitivamente en el cuerpo de la estructura significante, ya sea en forma de un motivo que conversa con las grandes cuestiones de cada novela particular, o en calidad de tema puro -como, considero, sucede en La inmortalidad-. La digresión y el énfasis en la reflexión, propios de este narrador, que algunas veces interpela al lector como solían hacerlo de forma lúdica los narradores de la novela dieciochesca, autorizan el ingreso explícito del problema de la novela, la historia de la novela y el arte de su composición. Veamos:

Sería estúpido que el autor tratase de convencer al lector de que sus personajes están realmente vivos. No nacieron del cuerpo de sus madres, sino de una o dos frases sugerentes o de una situación básica. Tomás nació de la frase "einmal ist keinmal". Teresa nació de una barriga que hace ruido. (Kundera, 1993, p. 43) 
Entradas como la anterior se harán bastante frecuentes en el periodo de la novelística kunderiana que inaugura La vida está en otra parte. $\mathrm{Su}$ lectura cuidadosa permite realizar algunas observaciones fundamentales. En primer lugar, se hace perfectamente evidente que un comentario como este corta de plano la continuidad de la trama, eso que se denomina la unidad de acción. Privilegiada la voz del narrador y, con esto, sus comentarios de corte reflexivo, entra el problema de la ficción literaria. Un personaje es un constructo ficticio, un producto de la imaginación del autor, un ego experimental (Kundera, 1987, p. 42) que encarna un código existencial (p. 40):

\section{Al escribir La insoportable levedad del ser me di cuenta de que el código de tal o cual personaje se compone de algunas palabras-clave. Para Teresa: el cuerpo, el alma, el vértigo, la debilidad, el idi- lio, el Paraíso. Para Tomás: la levedad, el peso. (1987, p. 40)}

El pacto de lectura que se establece con el lector asume la anterior condición como una verdad. En segundo lugar, la nota instituye y explica, hasta cierto punto, cómo comprende el autor la naturaleza de su arte. Mucho más adelante, adentrados en la quinta parte de La insoportable levedad del ser, aparece la siguiente acotación por parte del narrador que merece nuestra entera atención: "una novela no es una confesión del autor, sino una investigación sobre lo que es la vida humana dentro de la trampa en que se ha convertido el mundo" (Kundera, 1993, p. 223).

Lo que se hace evidente en este comentario es una intensión por definir o, al menos, por delimitar la esencia de la novela. La función cognoscitiva y noética de la novela, junto a la tarea de descubrir diferentes aspectos de la existencia humana, se manifiestan abiertamente a través de esta digresión del narrador que, puesta en contexto, suspende durante el breve trayecto de sus líneas el curso de la trama. En este sentido, Chvatik observa de manera muy acertada que "la tensión básica sobre la que descansa la construcción de las obras de Kundera [es] la tensión entre la historia y el comentario del narrador" (1996, p. 127) No en vano, una vez se culmina este comentario, el narrador prosigue del siguiente modo: "Pero basta. Volvamos a Tomás” (Kundera, 1993, p. 223). Examinemos ahora un pasaje de La inmortalidad:

La iteración puede llegar a convertirse en un buen recurso si el deseo es dar a entender algo.

Ahora está de pie justo al lado de la cama y la veo por primera vez desnuda, a Agnes, la heroína de mi novela. No soy capaz de apartar los ojos de esta hermosa mujer y ella, como si sintiera mi mirada, corre a vestirse a la habitación contigua.

¿Quién es Agnes?

Al igual que Eva, provino de la costilla de Adán, al igual que Venus nació de la espuma del mar, Agnes surgió del gesto de esa señora de sesenta años que levanta el brazo para despedirse en la piscina del instructor y cuyos rasgos ya se diluyen en mi memoria. (Kundera, 1990, p. 15)

Como se habrá podido entrever, se trata de una digresión muy similar a la que empleara para explicar el surgimiento de los personajes de Teresa y Tomás en La insoportable levedad 
del ser. En este caso, el poder de la digresión es empleado aquí por Kundera para poner de manifiesto el carácter ficcional de la narración y para establecer el pacto de lectura con el posible lector. Nótese lo temprano que en esta ocasión el autor cuida de realizar está indicación.

Ninguna de sus novelas ha sido escrita con mayor soltura y elegancia, con tanto placer por jugar con ideas paradójicas [como La inmortalidad]. Si dividimos las novelas de Kundera en dos grupos, en el primero, dedicado a cuestiones antropológicas, sociales y filosóficas relevantes, incluiríamos La broma, La vida está en otra parte y El libro de la risa y el olvido. Al segundo grupo, dedicado a historias de amor y al placer de la narración, pertenecen El libro de los amores ridículos, La despedida y La insoportable levedad del ser (aunque la estructura temática de esta última es más rica y compleja y se saldría de la clasificación). La inmortalidad es una acertada síntesis de los motivos y temas de ambos grupos. (Chvatik, 1996, p. 127)

Si seguimos el razonamiento de Chvatik, se hace posible pensar que La inmortalidad, como balance de los estilos narrativos y de los más recurrentes temas kunderianos, es, más que un justo medio, una cima estable dentro del trayecto de la búsqueda estética emprendida por el autor. Igualmente, es donde de manera más clara y explícita aparece la novela y su arte de la composición como parte íntegra del cuerpo significante de la obra, es decir: como tema. Curiosamente, esto se corresponde con un tipo de identificación del narrador con el autor que tiene [en La inmortalidad] una doble función: en primer lugar, "presenta" la convencionalidad de la función narrativa al cuadrado, porque la ecuación "narrador=autor=personaje de la novela" es otra vez ficción literaria, una nueva máscara narrativa (esta vez, la máscara de sí mismo), ya que el personaje literario del narrador y autor Milan Kundera no presenta en el texto identificación biográfica alguna. En segundo lugar, porque al aparecer en el texto como personaje de la novela, el autor Milan Kundera toma distancia del medio francés en que se desarrolla: París está visto con los ojos de un autor de origen checo que se acuerda de Praga e interpreta en el texto brevemente su novela praguense La vida está en otra parte. (1996, pp. 131-132)

Sin duda alguna, será en La inmortalidad en donde de forma más lúdica, libre y mordaz, el autor-narrador y ahora personaje de la novela hará gala de sus facultades digresivas, hecho que debilitará notablemente el hilo de la historia o trama novelesca. Así, el asunto de la composición argumental de esta novela y de su recepción será particularmente un problema de lectura atenta: "Si el lector se salta una frase de mi novela, no la entenderá" (Kundera, 1990, p. 400). "Y en efecto, hay una serie de ligazones argumentales que al lector se le escapan fácilmente y que incluso los críticos pueden pasar por alto" (Chvatik, 1996, p. 134). ¿No es lo anterior un llamado al ejercicio de la memoria y del sentido crítico-reflexivo? Tal como se muestra el narrador a través de sus comentarios digresivos, en su ensayo novelesco titulado Homo sentimentalis que ocupa la cuarta parte de la novela y como personaje de la trama, no puedo imaginarme otra cosa salvo el gesto de un rostro asintiendo. 


\section{A manera de corolario y conclusión: la poética de la novela kunderiana como postura crítica frente a la posmodernidad}

Con las ideas anteriores en mente, y a manera de cierre, ahora se hace necesario regresar al punto de partida, de lo contrario, la mención de los pasajes en que la novela se integra en el seno de la estructura significativa del universo literario de Kundera quedaría como un "gesto sin futuro". Si partimos del hecho de que cada una de sus novelas se ubica en un espacio temporal, histórico, social y cultural la galaxia de problemas y temas que tratan, del mismo modo, este marco sirve para comprender las exploraciones formales y narrativas que el autor lleva a cabo en la singularidad de cada uno de sus textos. Al recordar que la búsqueda estética conmensurada en la obra completa del autor de Los testamentos traicionados es, en sí misma, una crítica del panorama sociocultural que debió enfrentar a la hora de comprenderse en el oficio del novelista, es preciso esclarecer contra qué elementos está reaccionando.

El mundo se convirtió en una trampa para el hombre y en un ambiente hostil para el desarrollo de la novela en el momento en que se olvidó de su Historia para vivir en un estado de perenne actualidad acrítica y ahistórica. La trampa del mundo, entendida como metáfora, se identifica entonces con la etapa de los totalitarismos: la era de la vigilancia ininterrumpida de la actividad cotidiana del hombre que derivó, entre otras cosas, en la disolución de la frontera entre lo público y lo privado. La transparencia con la cual debía vivir el hombre en el estado totalitario, lejos de ser un modus vivendi idílico, se convirtió en una atopía desgarradora: la pérdida de la intimidad, de la individualidad, del libre pensamiento, en otras palabras, la paradoja de la disolución de los valores modernos en plena modernidad. La situación no fue muy diferente en Occidente, a pesar de la aparente gloria de sus democracias. En esta oportunidad, la trampa del mundo, representada en el objetivo vigilante y violador de la cámara, configuró un mundo donde "nadie tiene donde esconderse y [...] cualquiera está a merced de cualquiera" (Kundera, 1990, p. 43).

Los desastres resultantes de los totalitarismos político-ideológicos son acentuados por la mencionada mediatización del mundo, que se convirtió en la encargada de construir el nuevo espíritu de la época al sustituir el mito, la religión, la técnica y la ideología (Chvatik, 1996). Los medios de comunicación de masas, al imponer su imperio de la información, desvincularon al hombre de su capacidad crítica, reflexiva e imaginativa y la sustituyeron por la radio, la televisión, el internet, la publicidad y la moda. Esto es lo que en La inmortalidad se entiende como el derrocamiento de la ideología por la imagología, cuya más honda repercusión es haber confundido y suplantado el ser, la identidad, el yo, por una imagen. Asimismo, el mundo de la imagología no es otra cosa que, en buena medida, el "totalitarismo kitsch" del que nos habla Padilla (2010). Al producir hecatombes comparables a las de los totalitarismos políticos, en el mundo del kitsch todo se convierte en algo feo, como nos insinuará constantemente y con tristeza Agnes a lo largo de la novela.

¿Por qué, entonces, la inmersión de una poética de la novela dentro de la novela misma puede interpretarse como un gesto de repudio contra este mundo que ha entrado en una etapa de colapso cultural? La respuesta es una iteración: solo dentro de la historia de la novela el sentido de la función estética del género es capaz de 
validarse como un valor. Solo el gesto de recobrar la conciencia histórica nos salvará del "olvido del ser" del que habla Husserl, en la medida en que allí se reivindica el sentido de la existencia humana. De modo que, solo desde el interior de la herencia de Cervantes la novela se salvará de convertirse en otro producto del kitsch y se podrá convertir -a pesar de la precariedad de su gesto en un mundo donde pocos leen y muchos simplemente se extasían sensualmente ante el placebo de la imagen- en el nomeolvides que Agnes se comprará el día en que el mundo se desboque en el límite de la frontera que no debía cruzar. La novela es, entonces, como tema dentro de la novela, un gesto de remembranza de una tradición que siempre propendió por evaluar la existencia humana desde la perspectiva de lo bello; tradición que, como se expresó inicialmente, es una venganza contra la Historia (con mayúscula) y su desgraciado progreso que paradójicamente, en algún punto, aplastó al ser humano.

\section{Referencias}

Chvatik, K. (1996). La trampa del mundo: Milan Kundera, novelista. Barcelona: Tusquets.

Kundera, M. (1987). El arte de la Novela. Barcelona: Tusquets.

Kundera, M. (1990). La inmortalidad. Barcelona: Tusquets.

Kundera, M. (1993). La insoportable levedad del ser. Barcelona: Tusquets.

Kundera, M. (1994). Los testamentos traicionados. Barcelona: Tusquets.

Mukařovský, J. (2000a). El arte como hecho sígnico. En J. Jandová y E. Volek (eds), Signo, función y valor: estética y semiótica del arte de Jan Mukařovský (pp. 88-95). Bogotá: Plaza \& Janés.

Mukařovský, J. (2000b). El concepto de totalidad en la teoría del arte. En J. Jandová y E. Volek (eds), Signo, función y valor: estética y semiótica del arte de Jan Mukařovský (pp. 290302). Bogotá: Plaza \& Janés.

Padilla, I. (2010). Milan Kundera y el totalitarismo kitsch: dictadura de conciencias y demagogia de sentimientos. Bogotá: Universidad Nacional de Colombia. 